\title{
Pelvic floor muscle strength evaluation in different body positions in nulliparous healthy women and its correlation with sexual activity
}

Mônica Orsi Gameiro, Luciana Miraglia, Luiz Felipe Orsi Gameiro, Carlos Roberto Padovani, João Luiz Amaro

Physiotherapy Service (MOG, LM, LFOG); Department of Biostatistics (CRP) and Department of Urology (JLA) School of Medicine, São Paulo State University, Botucatu, SP, Brazil

\section{ABSTRACT}

Objective: The aim of this study was to assess pelvic floor muscle (PFM) strength in different body positions in nulliparous healthy women and its correlation with sexual activity. Materials and Methods: Fifty healthy nulliparous women with mean age of 23 years were prospectively studied. Subjective evaluation of PFM was assessed by transvaginal digital palpation (TDP) of anterior and posterior areas regarding the vaginal introitus. A perineometer with inflatable vaginal probe was used to assess the PFM strength in four different positions: supine with extended lower limbs (P1); bent-knee supine (P2); sitting (P3); standing (P4).

Results: Physical activity, 3 times per week, was reported by 58\% of volunteers. Sexual activity was observed in $80 \%$ of women and $82 \%$ of them presented orgasm. The average body mass index (BMI) was $21.76 \mathrm{~kg} / \mathrm{m}^{2}$, considered as normal according World Health Organization (WHO). We observed that 68\% of volunteers were conscious about the PFM contraction. TDP showed concordance of 76\% when anterior and posterior areas were compared $(\mathrm{p}=0.00014)$. There was not correlation between PFM strength and orgasm in subjective evaluation. The PFM strength was significantly higher in standing position when compared with the other positions $(p<0.000)$. No statistical difference was observed between orgasm and PFM strength when objective evaluations were performed.

Conclusions: There was concordance between anterior and posterior areas in $76 \%$ of cases when subjective PFM strength was assessed. In objective evaluation, higher PFM strength was observed when volunteers were standing. No statistical correlation was observed between PFM strength and orgasm in nulliparous healthy women.

\section{ARTICLE INFO}

\section{Key words:}

Muscle Strength; Pelvic Floor; Sexual Behavior; Parity

Int Braz J Urol. 2013; 39: 847-52

Submitted for publication:

March 11, 2013

Accepted after revision:

September 16, 2013

\section{INTRODUCTION}

The vagina and bladder are correlated to the pelvic floor muscles (PFM), comprising the elevator ani and puborectalis. Likewise, decrease of pelvic floor muscle (PFM) strength in women may cause urinary incontinence (UI) (1) or sexual disorders (2). The recovery of these muscles could be therapeutic $(3,4)$. On the other hand, Dietz et al. (5), studying nulliparous women, reported that pelvic floor musculature was strongly required during sexual intercourse, and increased elevator activity was also observed. These facts suggest a possible correlation between sexual activity and 
stronger pelvic floor muscle. Some studies report a relationship between women's sensation during sexual intercourse as well as the vaginal grip intensity felt by their partner $(6,7)$. Puborectalis muscle may play an important role in the constrictor function of PFM. Thus, its assessment, by vaginal pressure measurement, could be a determinant factor for PFM evaluation $(8,9)$.

Some authors have advocated different forms of PFM assessment using tools such as ultrasound (10), electromyography (EMG) (11) and magnetic resonance imaging (MRI) (12). These different approaches may also permit to evaluate other aspects of PFM activity when compared with vaginal squeeze pressure.

Another important point would be women's body position during pelvic floor evaluation. Another study observed that digital muscle testing and vaginal pressures using manometry are reliable tools for measuring maximum voluntary contraction in supine and upright positions (13). However, there is no consensus on the best form to evaluate the PFM strength as well as its baseline concerning nulliparous healthy women and its relationship with sexual activities. Thus, we propose to assess PFM strength in different body positions and also to evaluate its correlation with sexual activity in this specific population.

\section{MATERIALS AND METHODS}

From March to September 2006, fifty healthy nulliparous volunteers of healthy area were recruited by an invitation letter. Mean age was 23 years old (range 20-30). The group comprised women with higher education level (University). This study was approved by the "Ethical Research Committee" (protocol n.368/2005). All participants were informed about its importance and signed the "Free Informed Consent".

Exclusion criteria were UI or urinary complaints, neurological diseases, previous pelvic surgeries, diabetes, smoking and cognitive problems.

Women were evaluated through a clinical questionnaire. Sexual activity was assessed by self-applicable anonymous questionnaire, composed of two simples questions: 1 - Have you had sexual intercourse in the last 3 months? Yes/ No;
2 - Did you have orgasm during this intercourse? Yes/ No. BMI was calculated and classified according to the World Health Organization (WHO) (14). Subjective and objective PFM evaluations were performed in all women.

For the subjective evaluation, volunteers were placed in supine position, undressed from waist to feet, covered with a sheet with the lower limbs bent and separated and instructed about the correct PFM contraction. They were evaluated by only one examiner through transvaginal digital palpation (TDP) of anterior and posterior areas regarding the vaginal introitus (Figure-1); they were also required to contract the perineal muscles and hold this contraction as long as possible. The classification of the PFM strength contraction

\section{Figure 1 - Bidigital vaginal palpation regarding the vaginal introitus. (A) anterior and (B) posterior areas.}

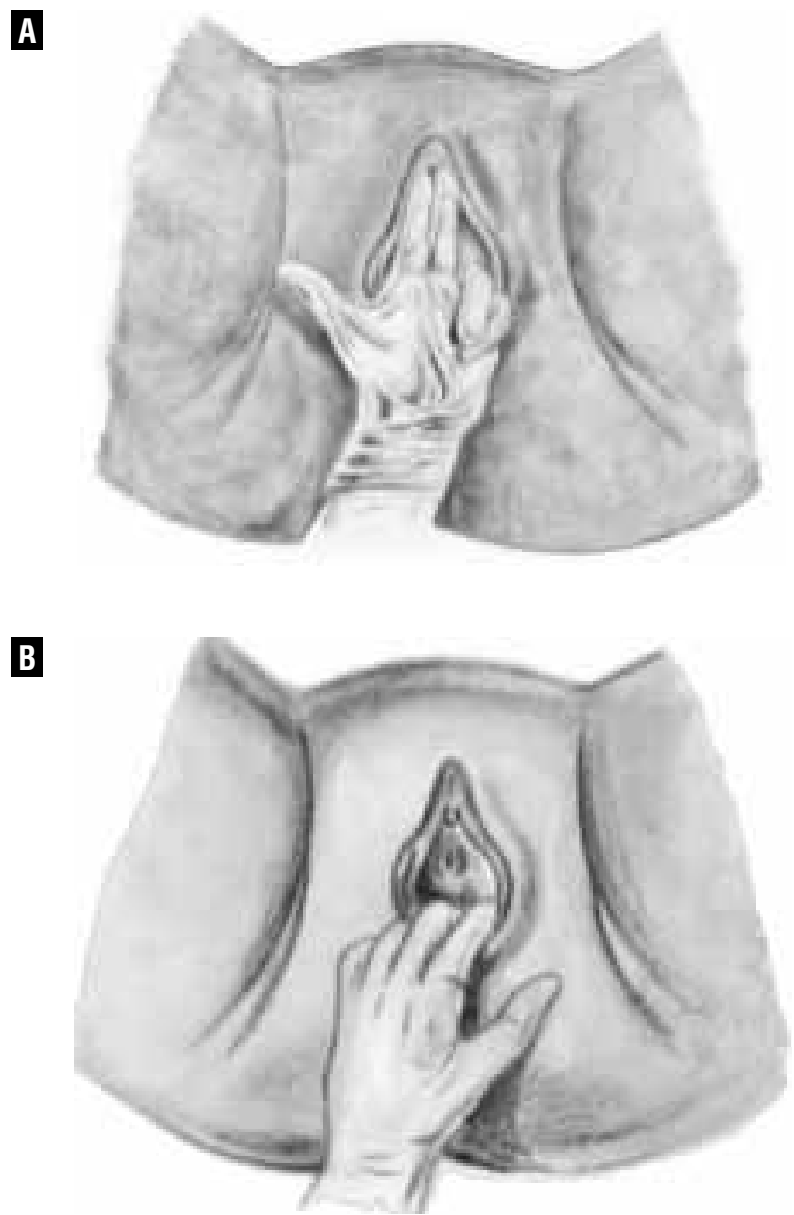


was performed according to the description of Amaro et al. (4), that it has been tested but not validated.

The objective measurement was obtained with a Dynamed portable perineometer (model DM01), in four different patient positions (Figure-2): supine with lower limbs extended $\left(\mathrm{P}_{1}\right)$; bent-knee lying $\left(\mathrm{P}_{2}\right)$, sitting $\left(\mathrm{P}_{3}\right)$, and standing $\left(\mathrm{P}_{4}\right)$. When the participants were in position, examiner introduced a balloon catheter, sized $11 \times 2.6 \mathrm{~cm}$, into the vagina. The balloon catheter was covered with a non-lubricated condom, and filled with $60 \mathrm{~mL}$ of air permitting contact with the vaginal wall. This value was standardized at $60 \mathrm{~mL}$ in all participants. The equipment was immediately zeroed, three PFM contractions were requested and held as long as possible with nearly 30-second of rest interval between each one. Maximal peak of each contraction was registered in $\mathrm{cmH}_{2} \mathrm{O}$. The length of time of these contractions was recorded in seconds with chronometer. The average of three measurements was used to avoid biased results.

\section{Statistical analysis}

Qualitative variables were analyzed using the proportion test of concordances (15). Mann-Whitney Test was used for comparisons between PFM strength and the presence or not of orgasm. For the comparison of PFM strength in different body positions, the Friedman's non-parametric test was used and complemented by the Dunn multiple comparison tests. For comparing the time of PFM contractions, the technique of variance analysis for measurements of repeated models was used and complemented by Bonferroni's test (16). Statistical analysis was performed at 5\% of significance level.

\section{RESULTS}

The mean age of women's menarche was 12 years old. Sexual activity was reported by $80 \%$ and $82 \%$ of these women reported orgasm. Regular physical activity, at least three times a week, was

Figure 2 - Pelvic floor muscle assessment using manometry testing in four different positions. $P_{1}:$ supine. $P_{2}$ : Bent-knee lying. $\mathbf{P}_{3}$ : Sitting. $\mathbf{P}_{4}$ : Standing.

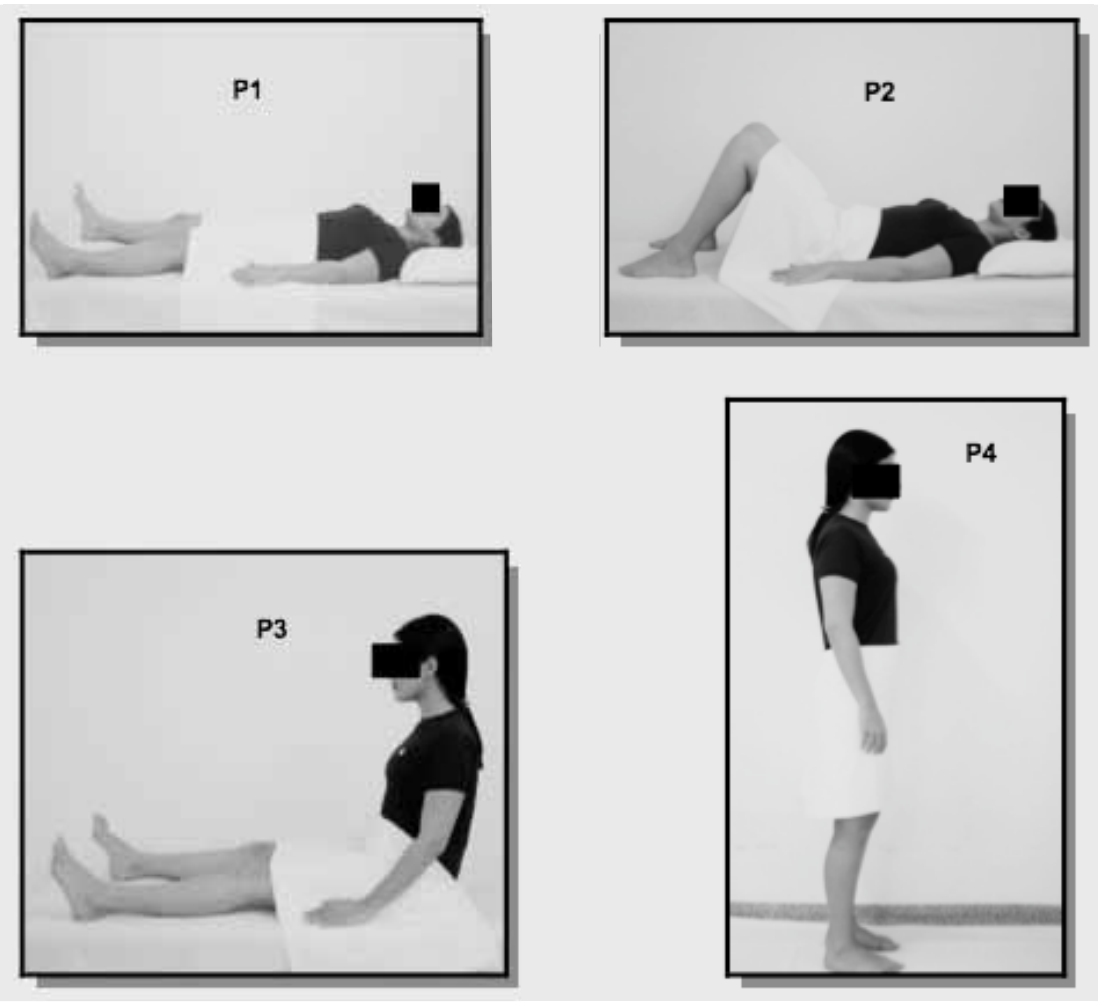


reported by 58\% of volunteers and 54\% of them presented symptoms of constipation.

Average BMI was $21.76 \mathrm{Kg} / \mathrm{m}^{2}$, considered as normal according to WHO.

PFM subjective evaluation showed that $68 \%$ of women were conscious of musculature contraction. The TDP in anterior position showed that $48 \%$ and $52 \%$ of women had moderate and normal PFM contractions, respectively. Whereas, in posterior area, we observed that moderate and normal contractions represented $24 \%$ and $72 \%$ respectively. There was statistical concordance in $76 \%$ of cases $(p<0.00014)$ when both positions of PFM evaluation were compared (Table-1). However, there was no statistical correlation between orgasm and subjective PFM evaluation neither in anterior nor in posterior areas regarding the vaginal introitous.

Perineometer evaluation of PFM strength was significantly higher in standing position when compared to the others (Table-2). Time of PFM contraction was significantly longer in the standing position (Table-3). There was not statistical difference in the PFM strength, in the different test positions, in women with orgasm compared to those who had not orgasm (Table-3).

\section{DISCUSSION}

Mean age of menarche was 12 years old what is in agreement with literature (17). Some authors consider menarcheal age important because

Table 1 - Association between the bidigital vaginal palpation in anterior and posterior areas of vaginal introitus according to Amaro's classification (4).

\begin{tabular}{lccc}
\hline SE posterior & & SE anterior & \\
\cline { 2 - 4 } & Grade 2 & Grade 3 & Total \\
\hline Grade 2 & $12(24 \%)^{*}$ & $0(0.0 \%)$ & $12(24 \%)$ \\
Grade 3 & $12(24 \%)$ & $26(52 \%)^{*}$ & $38(76 \%)$ \\
\hline Total & $\mathbf{2 4 ( 4 8 \% )}$ & $\mathbf{2 6 ( 5 2 \% )}$ & $\mathbf{5 0 ( 1 0 0 \% )}$ \\
\hline
\end{tabular}

* Concordance level in moderate grade $=24 \%$ and normal grade $=52 \% ; p<0.00014$

SE $=$ Subjective Evaluation

Table 2 - Maximum amplitude $\left(\mathrm{cmH}_{2} \mathrm{O}\right)$ (median and range) and time (second) (mean $\pm \mathrm{sd}$ ) of PFM contractions in objective evaluation of PFM strength using perineometer $\left(\mathrm{cmH}_{2} \mathrm{O}\right)$ in different positions. Different lower case letters indicate when groups were significantly different at the same moment.

\begin{tabular}{|c|c|c|c|c|c|}
\hline \multirow[b]{2}{*}{ Objective evaluation of PFM } & \multicolumn{4}{|c|}{ Body Position } & \multirow[b]{2}{*}{$\begin{array}{l}\text { Statistical } \\
\text { Analysis }\end{array}$} \\
\hline & $P_{1}$ & $P_{2}$ & $\mathrm{P}_{3}$ & $\mathrm{P}_{4}$ & \\
\hline $\begin{array}{l}\text { Median and range of PFM } \\
\text { strength }\left(\mathrm{CmH}_{2} \mathrm{O}\right)\end{array}$ & $\begin{array}{c}16.30 \mathrm{a} \\
(6.6-55.3)\end{array}$ & $\begin{array}{c}15.60 \mathrm{a} \\
(7.0-59.0)\end{array}$ & $\begin{array}{c}19.30 \mathrm{a} \\
(3.6-87.3)\end{array}$ & $\begin{array}{c}28.65 b \\
(12.6-96.3)\end{array}$ & $p<0.000$ \\
\hline $\begin{array}{l}\text { Mean and Standard deviatior } \\
\text { of PFM contraction time } \\
\text { (second) }\end{array}$ & $7.26 \pm 1.72 a$ & $7.16 \pm 1.33 a$ & $7.68 \pm 1.75 a$ & $8,45 \pm 2.33 b$ & $p<0.000$ \\
\hline
\end{tabular}

P1: supine; P2: Bent-Knee lying; P3: Sitting; P4: standing 
Table 3 - Association between Maximum amplitude $\left(\mathrm{cmH}_{2} \mathrm{O}\right)$ (median and range) of PFM contractions in objective evaluation of PFM strength using perineometer in different positions and presence or not of orgasm.

\begin{tabular}{lccc}
\hline $\begin{array}{l}\text { PFM Strength in different body } \\
\text { positions }\left(\mathrm{cmH}_{2} \mathrm{O}\right)\end{array}$ & Obsent $(9 / 50-18 \%)$ & Prgasm & \\
& $14.30(6.60-27.00)$ & $16.60(6.60-55.30)$ & Statistical Analysis \\
\hline $\mathrm{P}_{1}$ (range) & $15.30(8.00-34.30)$ & $15.60(7.00-59.00)$ & $\mathrm{p}=0.357$ \\
$\mathrm{P}_{2}$ (range) & $15.60(6.00-36.00)$ & $20.00(3.60-87.30)$ & $\mathrm{p}=0.919$ \\
$\mathrm{P}_{3}$ (range) & $30.60(15.60-92.30)$ & $27.30(2.60-96.00)$ & $\mathrm{p}=0.086$ \\
$\mathrm{P}_{4}$ (range) & & $\mathrm{p}=0.649$ \\
\hline
\end{tabular}

$\mathbf{P}_{1}$ : supine; $\mathbf{P}_{2}$ : Bent-Knee lying; $\mathbf{P}_{3}$ : Sitting; $\mathbf{P}_{4}$ : standing

it is influenced by environmental and genetic factors, and also it may be determinant for sexual maturity (17), demonstrating that our population presents these homogenous characteristics.

In our population, BMI was considered normal according to WHO, demonstrating that obesity did not influence outcomes. Some authors consider that this fact could worsen SUI or pelvic disorders $(18,19)$. In our study, there was not influence of this parameter in the results.

Frawley et al. (13), using different methods for PFM evaluation, observed higher reliability using manometry in comparison to TDP assessment. However, other authors (20) reported a strong correlation between EMG and TDP in continent women without PFM disorders, showing that the best methods of PFM assessment are somehow controversial. In our study, we assessed PFM strength through transvaginal digital palpation in anterior and posterior areas and observed statistical concordance between both methods in $76 \%$ of cases, demonstrating that this assessment may be used in any of these positions. At the moment, there is no report regarding this subject in literature.

Maximum amplitude and time of PFM contractions in objective evaluation of PFM strength using perineometer in standing position were significantly higher in comparison to the other positions. This fact could be explained because in standing position the pelvic floor muscles suffer of gravity effects and respond with their contraction thereby increasing their strength.
Some authors reported the relation between orgasm and sexual arousal and PFM strength (7). Other authors observed that PFM function improvement using perineal exercise postpartum (21) or surgical procedure performed to pelvic floor dysfunctions can improve the sexual function (22). In our series, there was no statistical correlation between PFM strength and orgasm. The fact that we have not used a more specific and complete sexual function questionnaire, which could cause bias, suggests that further research in specific population is necessary.

\section{CONCLUSIONS}

There was statistical concordance in 76\% of cases when PFM strength, in anterior and posterior areas, was assessed using transvaginal digital palpation. Objective evaluation of PFM strength was significantly higher in standing position when compared to the other positions. Orgasm does not seem to be affected by PFM strength. Further studies should be performed in nulliparous continent women to elucidate the effects of different test positions and orgasm in the pelvic floor muscle strength.

\section{ABBREVIATIONS}

$\mathrm{PFM}=$ pelvic floor muscle)

TDP $=$ transvaginal digital palpation

WHO = World Health Organization

BMI = body mass index 
$\mathrm{UI}=$ urinary incontinence

EMG = electromyography

MRI $=$ resonance imaging

SUI $=$ stress urinary incontinence

\section{CONFLICT OF INTEREST}

None declared.

\section{REFERENCES}

1. Amaro JL, Moreira EC, De Oliveira Orsi Gameiro M, Padovani CR: Pelvic floor muscle evaluation in incontinent patients. Int Urogynecol J Pelvic Floor Dysfunct. 2005; 16: 352-4.

2. Shafik A: The role of the levator ani muscle in evacuation, sexual performance and pelvic floor disorders. Int Urogynecol J Pelvic Floor Dysfunct. 2000; 11: 361-76.

3. Zahariou AG, Karamouti MV, Papaioannou PD: Pelvic floor muscle training improves sexual function of women with stress urinary incontinence. Int Urogynecol J Pelvic Floor Dysfunct. 2008; 19: 401-6.

4. Amaro JL, Oliveira Gameiro M0, Padovani CR: Treatment of urinary stress incontinence by intravaginal electrical stimulation and pelvic floor physiotherapy. Int Urogynecol J Pelvic Floor Dysfunct. 2003; 14: 204-8; discussion 208.

5. Dietz HP, Steensma AB, Vancaillie TG: Levator function in nulliparous women. Int Urogynecol J Pelvic Floor Dysfunct. 2003; 14: 24-6; discussion 26.

6. Graber B, Kline-Graber G: Female orgasm: role of pubococcygeus muscle. J Clin Psychiatry. 1979; 40: 348-51.

7. Lowenstein L, Gruenwald I, Gartman I, Vardi Y: Can stronger pelvic muscle floor improve sexual function? Int Urogynecol J. 2010; 21: 553-6.

8. Jung SA, Pretorius DH, Padda BS, Weinstein MM, Nager CW, den Boer DJ, et al.: Vaginal high-pressure zone assessed by dynamic 3-dimensional ultrasound images of the pelvic floor. Am J Obstet Gynecol. 2007; 197: 52.e1-7.

9. Brandon CJ, Lewicky-Gaupp C, Larson KA, Delancey JO: Anatomy of the perineal membrane as seen in magnetic resonance images of nulliparous women. Am J Obstet Gynecol. 2009 ; 200: 583.e1-6.

10. Santoro GA, Wieczorek AP, Dietz HP, Mellgren A, Sultan AH, Shobeiri SA, et al.: State of the art: an integrated approach to pelvic floor ultrasonography. Ultrasound Obstet Gynecol. 2011; 37: 381-96.
11. Peschers UM, Voduŝek DB, Fanger G, Schaer GN, DeLancey J0, Schuessler B: Pelvic muscle activity in nulliparous volunteers. Neurourol Urodyn. 2001; 20: 269-75.

12. Soljanik I, Janssen U, May F, Fritsch H, Stief CG, Weissenbacher ER, et al.: Functional interactions between the fossa ischioanalis, levator ani and gluteus maximus muscles of the female pelvic floor: aprospective study in nulliparous women. Arch Gynecol Obstet. 2012; 286: 931-8.

13. Frawley HC, Galea MP, Phillips BA, Sherburn M, Bø K: Reliability of pelvic floor muscle strength assessment using different test positions and tools. Neurourol Urodyn. 2006; 25: 236-42.

14. World Health Organization [homepage on the Internet] (2006) BMI Classification. Geneva: WHO [cited 2008 nov 1 12]. Available from: www.who.int/bmi.

15. Goodman LA: Simultaneus confidence intervals for multinomial proportions. Technometrics. 1965; 7: 247-54.

16. Zar JH: Biostatical analysis. New Jersey, Prentice Hall. 2009; 5th Ed., pp. 1-960.

17. Tavares CH, Haeffner LS, Barbieri MA, Bettiol H, Barbieri MR, Souza L: Age at menarche among schoolgirls from a rural community in Southeast Brazil. Cad Saude Publica. 2000; 16: 709-15.

18. Viktrup L: Female stress and urge incontinence in family practice: insight into the lower urinary tract. Int J Clin Pract. 2002; 56: 694-700.

19. Kirby M: Managing stress urinary incontinence -- a primary care issue. Int J Clin Pract. 2006; 60: 184-9.

20. Botelho S, Pereira LC, Marques J, Lanza AH, Amorim CF, Palma $P$, et al.: Is there correlation between electromyography and digital palpation as means of measuring pelvic floor muscle contractility innulliparous, pregnant, and postpartum women? Neurourol Urodyn. 2013; 32: 420-3.

21. Citak N, Cam C, Arslan H, Karateke A, Tug N, Ayaz R, et al.: Postpartum sexual function of women and the effects of early pelvic floor muscle exercises. Acta Obstet Gynecol Scand. 2010; 89: 817-22.

22. Kammerer-Doak D: Assessment of sexual function in women with pelvic floor dysfunction. Int Urogynecol J Pelvic Floor Dysfunct. 2009; 20(Suppl 1): S45-50.

Correspondence address: João Luiz Amaro, MD

Faculdade de Medicina de Botucatu, Departamento de Urologia Botucatu, São Paulo, 18618-970, Brasil Telephone: + 55014 3811-6271 E-mail: jamaro@fmb.unesp.br 